\title{
COMMUNITY-ACQUIRED PNEUMONIA IN UGANDAN ADULTS: SHORT-TERM PARENTERAL AMPICILLIN THERAPY FOR BACTERIAL PNEUMONIA
}

\author{
HIROYUKI YOSHIMINE, KAZUNORI OISHI, FRANCIS MUBIRU, \\ HAWA NALWOGA, HIDEHIKO TAKAHASHI, HIDEAKI AMANO, \\ PHILIP OMBASI, KIWAO WATANABE, MOSES JOLOBA, THOMAS AISU, \\ KAMRUDDIN AHMED, MASAAKI SHIMADA, ROY MUGERWA, \\ AND TSUYOSHI NAGATAKE \\ Department of Internal Medicine and Information and Reference Center, Institute of Tropical Medicine, Nagasaki University, \\ Nagasaki, Japan; Department of Medicine and Microbiology, Makerere University, Kampala, Uganda
}

\begin{abstract}
A hospital-based prospective study of 99 patients with community-acquired pneumonia (CAP) was carried out in Kampala, Uganda. We evaluated microbiological etiologies, clinical features and effectiveness of shortterm parenteral ampicillin followed by oral amoxicillin for these patients in relation to HIV-status. We demonstrated a very high prevalence (75\%) of HIV-1 infection. No significant difference was observed with respect to age, gender, prior antibiotic usage, symptoms, laboratory data or bacterial etiology between HIV-1-infected and HIV-uninfected CAP patients. Most strains of Streptococcus pneumoniae $(\mathrm{n}=19)$ and Haemophilus influenzae $(\mathrm{n}=8)$ isolated from HIV-1-infected patients were penicillin-resistant $(95 \%)$ and $\beta$-lactamase producing $(75 \%)$ strains, respectively. A high percentage of good clinical response was found in both HIV-1-infected (81\%) and HIV-uninfected (86\%) among 39 patients with CAP due to a defined bacterial pathogen. These data support the use of short-term parenteral ampicillin for patients with bacterial CAP irrespective of HIV-status.
\end{abstract}

\section{INTRODUCTION}

Acute respiratory infections commonly cause morbidity and mortality in tropical and developing countries. ${ }^{1} \mathrm{~A}$ changing pattern of these diseases has, however, been recognized especially in sub-Saharan Africa, where there is a high seroprevalence of HIV infection. ${ }^{2}$ Although the incidence of opportunistic infections in HIV-infected persons has decreased in industrialized countries following the initiation of antiretroviral therapy, the social and medical situation of HIV-infected persons in sub-Saharan Africa remains unchanged. ${ }^{3}$ The high HIV infection rate among patients with pneumonia or acute respiratory illness supports the hypothesis that HIV infection is an important risk factor for these diseases in these areas. ${ }^{4,5} \mathrm{~A}$ recent study in the United States demonstrated that bacterial pneumonia is more frequent in $\mathrm{HIV}$-infected persons than HIV-uninfected persons, and the risk is highest among those with CD4 lymphocyte counts less than 200/ $\mu 1$. $^{6}$ A substantial dysfunction of humoral immunity associated with HIV infection appears to predispose to bacterial pneumonia in these patients. ${ }^{7}$

Previous investigators have demonstrated that penicillin is cost-effective in the treatment of lobar pneumonia before the outbreak of HIV infection in Africa. ${ }^{8,9}$ A recent paper from India also emphasized the need for a cost-effective approach to treatment of CAP, for example with the use of parenteral penicillin in developing countries. ${ }^{10}$ Moreover, Siegel and colleagues similarly demonstrated the cost-effectiveness of short-term parenteral therapy with cephalosporins for CAP in the US. ${ }^{11}$ On the other hand, two recent studies in Africa have demonstrated the etiologic diagnosis and outcome of patients with community-acquired pneumonia (CAP). These studies reported relatively low frequencies of HIV infection among these patients (8\% in Ethiopia and $26 \%$ in Cameroon), but did not focus on the effectiveness of antibiotic treatment. ${ }^{12,13}$ Therefore, the clinical effectiveness of shortterm parenteral therapy against bacterial CAP in HIV-infected and HIV-uninfected patients in HIV-endemic, developing countries is not well documented.
In this study, we evaluated the clinical and microbiological features of adult patients with CAP as well as the clinical effectiveness of short-term parenteral ampicillin followed by oral amoxicillin for bacterial CAP in Uganda, a country in which HIV-1 infection is very prevalent.

\section{PATIENTS AND METHODS}

Patients. Between November 1996 and March 1998, 99 patients admitted with CAP were enrolled by clinicians (F. M. and H. N.) at the Department of Medicine, Makerere Medical School, Kampala, Uganda, after written informed consent had been obtained from either the patient or the principal care giver. Inclusion criteria for this study were: (1) patients $>18 \mathrm{yrs}$ of age with a putative diagnosis of pneumonia made within $24 \mathrm{hr}$ of admission; (2) a new pulmonary infiltrate on chest radiograph; and (3) clinical observation of one major criterion (cough, sputum production, or temperature $>37.0^{\circ} \mathrm{C}$ ) or one minor criterion (white blood cell count $>9,000 / \mu$ l or a serum C-reactive protein (CRP, Wako Chemical Industries Ltd, Osaka, Japan) level $>$ $1.0 \mathrm{mg} / \mathrm{dl}$ ), according to previous reports. ${ }^{14,15}$ Patients in whom radiographic abnormalities were attributable to congestive heart failure or chronic underlying lung diseases were excluded. No antiretroviral therapy or HIV prophylactic treatments such as trimethoprim-sulfamethoxazole (TMPSMZ) or isoniazid had been prescribed for the HIV-infected patients. Prior antibiotic usage was defined as any prescribed or self-administrated antibiotics. The study protocol was reviewed and approved by the Ugandan National AIDS Research Committee and the National Council for Science and Technology of Uganda.

Microbiological examinations. Full evaluation included expectorated sputum for cytological screening $(<10$ epithelial cells and $>25$ polymorphonuclear cells per low power field), Gram's staining of a smear, quantitative sputum culture employing rabbit blood agar after homogenization with N-acetylcysteine (Senju Pharmaceutical Co., Osaka, Japan) 
as previously described. ${ }^{16}$ Acute phase and convalescent sera from patients were used for the antibody detection against Chlamydia pneumoniae (Hitachi Kasei Co. Ltd., Tokyo, Japan), ${ }^{17}$ Legionella species (Denka Seiken Co. Ltd., Tokyo, Japan), ${ }^{18}$ and Mycoplasma pneumoniae (Fuji Rebio Co. Ltd., Tokyo, Japan). Between 2 and 4 weeks after enrollment, convalescent sera were obtained and stored at $-80{ }^{\circ} \mathrm{C}$.

Classification of etiologic diagnosis. The criteria for etiologic diagnosis were 1) positive blood culture of bacterial pathogen; 2) a heavy growth of bacterial pathogen $\left[>10^{7}\right.$ colony-forming units $(\mathrm{cfu}) / \mathrm{ml}$ ] on sputum culture or a mild growth of bacterial pathogen $\left(>10^{6} \mathrm{cfu} / \mathrm{ml}\right)$ in which the Gram-staining of a smear revealed a predominant organism morphologically compatible with the culture result; 3 ) fourfold rise in an agglutination test for $M$. pneumoniae, in an ELISA titer of IgG for C. pneumoniae, or in an agglutination test for Legionella species; and 4) induced sputum revealing Mycobacterium tuberculosis only when M. tuberculosis was regarded to be attributable to CAP. ${ }^{14}$ When no specific microbiological diagnosis was made, the etiology was classified as unknown. No patients with associated conditions that predisposed to aspiration combined with a new infiltrate in a dependent pulmonary segment were noted.

Clinical and laboratory examinations. Within $24 \mathrm{hr}$ of admission, a physician examined the patients and recorded the findings on standardized case record forms. Diagnostic examinations involved a chest roentgenogram (PA view), complete blood count with differential, blood culture, and serum CRP. Hypoxemia, defined as arterial oxygen saturation $<90 \%$ was determined by oximetry (Nonin Medical, Inc., North Plymouth, MN) on the finger. ${ }^{19}$ HIV serostatus was determined for all the patients enrolled using particle agglutination (Fuji Rebio) and Western blot (Ortho Diagnostic Inc, Raritan, NJ). The CD4 and CD8 lymphocyte counts in the peripheral blood were examined by flow cytometry in each patient at the time of enrollment. This test was not performed for six patients (five HIV-1-infected, one HIV-uninfected).

In vitro susceptibility test. Minimum inhibitory concentrations (MICs) of penicillin G (Meiji Seika Kaisha Ltd, Tokyo, Japan), ampicillin (Meiji Seika Kaisha), sultamicillin (Pfizer Pharmaceutical, Tokyo, Japan), cefuroxime (Nippon Glaxo, Tokyo, Japan), cefmenoxime (Takeda Chemical Industries, Osaka, Japan), erythromycin (Dainippon Pharmaceutical Co. Ltd, Osaka, Japan), minocycline (Lederle Japan Ltd, Tokyo, Japan), gentamicin (Schering-Plough, Tokyo, Japan), ofloxacin (Daiichi Pharmaceutical Co, Tokyo, Japan) and TMP-SMZ (Shionogi \& Co. Ltd, Osaka, Japan) against 19 strains of Streptococcus pneumoniae and 8 strains of Haemophilus influenzae isolated from patients with CAP were determined by the agar dilution methods as recommended by the Japanese Society of Chemotherapy. ${ }^{20}$ Streptococcus pneumoniae were designated as susceptible (MIC $\leq 0.05 \mu \mathrm{g} / \mathrm{ml}$; PSSP), intermediately resistant (MIC. 0.1 to $0.78 \mu \mathrm{g} / \mathrm{ml}$; PISP), and resistant to penicillin G (MIC $\geq 1.56$ $\mu \mathrm{g} / \mathrm{ml}$; PRSP) according to the modified recommendations of the National Committee for Clinical Laboratory Standards. ${ }^{21} \beta$-lactamase production was determined by the Cefinase disk test (Becton Dickinson and Company, Cockeysville, MD) according to the manufacturer's instructions.

Treatment and clinical response. A short-term regimen of parenteral ampicillin (1 gram twice a day) for 3 days followed by 1.5 gram per day of oral amoxicillin for 4 to 7 days were given as the standard therapy for enrolled patients with CAP. Anti-tuberculosis drugs consisting of rifampin, pyrazinamide, ethambutol and isoniazid were given after the standard therapy in cases of suspected M. tuberculosis infection who were positive on Ziehl-Neelsen stain of sputum.

Twenty (fifteen HIV-1-infected and five HIV-uninfected) patients withdrew from the study before evaluation of effectiveness of antimicrobial therapy. There was no difference in proportion of HIV-1 infection and gender, and in age between evaluated and withdrawn patients. The effectiveness of antimicrobial therapy consisting of parenteral ampicillin was evaluated on patients with identified pathogens using the following criteria: 1) good response if the initial findings of chest radiograph improved and one major criterion (cough, sputum production, fever) and one minor criterion (a white blood cell count reduced to less than $9,000 / \mu 1$ or a serum CRP value lowered to $50 \%$ or less of the previous value) improved; 2) poor response if the initial findings of chest radiograph worsened, or one major or minor criterion worsened. ${ }^{15}$ The patients were examined at the Department of Medicine, Makerere University at day 1, day 3, day 7, and day 14 after enrollment. The findings on clinical examination and laboratory data were recorded at each of these visits after the enrollment.

Statistical analysis. Statistical comparisons of categorical clinical variables were made by Chi-square analysis or by Fisher's exact test, of CD4, CD8 lymphocyte count and the $\mathrm{CD} 4 / \mathrm{CD} 8$ ratio were made by Mann-Whitney $\mathrm{U}$ test. The comparison of clinical effectiveness stratified by HIV-status was made by Fisher's exact test. A $P$ value of $<0.05$ was considered significant.

\section{RESULTS}

Ninety-nine consecutive adult patients with CAP were evaluated. Among them 74 (75\%) were HIV-1-infected and $25(25 \%)$ were HIV-uninfected (Table 1). There was no significant difference in gender or age between these groups. The CD4 lymphocyte counts and the CD4/CD8 ratio in HIV1 -infected patients were significantly lower than those in HIV-uninfected $(P<0.0001)$. In contrast, the CD8 peripheral-blood lymphocyte counts in HIV-1-infected patients were significantly higher than those in HIV-uninfected $(P<$ $0.0001)$. More than $50 \%$ of the HIV-1-infected and HIVuninfected patients with CAP had high respiratory $(>30 /$ min) and heart rates $(>100 / \mathrm{min})$. More than $50 \%$ of the enrolled patients had hypoxemia, but did not receive oxygen therapy because of lack of facilities. Penicillin (21\%) and TMP-SMZ (12\%) were frequently noted as prior antibiotic use. The CD4 lymphocyte counts of the most $(73 \%)$ of the HIV-1-infected patients were less than 400/ $\mu$ l (Figure 1). This finding suggests a close relationship between HIV infection and the incidence of CAP. Before treatment, there were no significant differences between HIV + and HIVpatients with respect to demographic characteristics, age, gender, rate of prior antibiotic usage, respiratory and heart rate, or laboratory data including white blood cell counts, levels of hemoglobin, serum levels of CRP, the rate of hyp- 
TABLE 1

Clinical characteristics of hospitalized patients with community-acquired pneumonia by HIV-status in Uganda

\begin{tabular}{|c|c|c|c|}
\hline & \multicolumn{2}{|c|}{ HIV-status } & \multirow[b]{2}{*}{$P$ value } \\
\hline & $\begin{array}{l}\text { HIV-1 infected } \\
n=74 \\
(74.8 \%)\end{array}$ & $\begin{array}{c}\text { HIV-uninfected } \\
n=25 \\
(25.2 \%)\end{array}$ & \\
\hline Age, mean \pm SD & $33.2 \pm 9.8$ & $37.2 \pm 21.2$ & NS \\
\hline Males, n (\%) & $49(66.2)$ & $16(64.0)$ & NS \\
\hline \multicolumn{4}{|l|}{ Vital signs, $\mathrm{n}(\%)$} \\
\hline Temperature, $>38.5^{\circ} \mathrm{C}$ & $60(81.1)$ & $18(72.0)$ & NS \\
\hline Respiration rate, $>30 / \mathrm{min}$ & $44(59.5)$ & $13(52.0)$ & NS \\
\hline Heart rate, $>100 / \mathrm{min}$ & $45(61.7)$ & $15(60.0)$ & NS \\
\hline Prior antibiotic usage, $\mathrm{n}(\%)$ & $33(45.2)$ & $7(28.0)$ & NS \\
\hline \multicolumn{4}{|l|}{ Laboratory values, mean $\pm \mathrm{SD}$} \\
\hline WBC, $\times 10^{3} / \mu 1$ & $11.3 \pm 6.0$ & $12.9 \pm 6.4$ & NS \\
\hline CD4 cells/ $\mu \mathrm{l}$ & $329.8 \pm 285.0$ & $876.0 \pm 429.0$ & $<0.0001$ \\
\hline CD8 cells/ $\mu 1$ & $896.0 \pm 593.2$ & $384.3 \pm 239.0$ & $<0.0001$ \\
\hline CD4/CD8 ratio & $0.48 \pm 0.46$ & $2.60 \pm 1.13$ & $<0.0001$ \\
\hline Hemoglobin, g/dl & $11.3 \pm 2.9$ & $12.5 \pm 2.4$ & NS \\
\hline $\mathrm{CRP}, \mathrm{mg} / \mathrm{dl}$ & $16.5 \pm 10.5$ & $20.6 \pm 11.6$ & NS \\
\hline Hypoxemia, n (\%) & $42(56.8)$ & $13(52.0)$ & NS \\
\hline \multicolumn{4}{|l|}{ Lung involvement, $\mathrm{n}(\%)$} \\
\hline Multilobar & $24(32.4)$ & $14(56.0)$ & NS \\
\hline Pleural effusion, n (\%) & $9(12.2)$ & $3(12.0)$ & NS \\
\hline Oral candidiasis, n (\%) & $8(10.8)$ & 0 & NS \\
\hline
\end{tabular}

NS = not significant.

oxemia, and the rate of multilobar involvement and pleural effusion on chest radiograph.

At least one etiologic pathogen was identified in 48 cases (41 cases in HIV-1-infected and 7 cases in HIV-uninfected patients) among the enrolled patients (Table 2). The most common bacterial etiologies were $S$. pneumoniae (25 cases), H. influenzae (10 cases), Moraxella catarrhalis (8 cases), Staphylococcus aureus (5 cases) and Klebsiella pneumoniae ( 5 cases). Blood culture was positive in 6 cases: $S$. pneumoniae (4 cases) and Enterobacter cloacae (1 case) were found in HIV-1-infected patients; $S$. pneumoniae (1 case) was found in an HIV-uninfected patient. Two cases of CAP were found to be attributable to M. tuberculosis, although we identified this pathogen in 5 cases. Convalescent sera were obtained from all 99 patients. No four-fold rise in antibodies specific for $M$. pneumoniae, C. pneumoniae, and Legionella species was observed. Subsequently, 55 and 7 causative pathogens were identified in HIV-1-infected and HIV-uninfected patients, respectively. No difference was

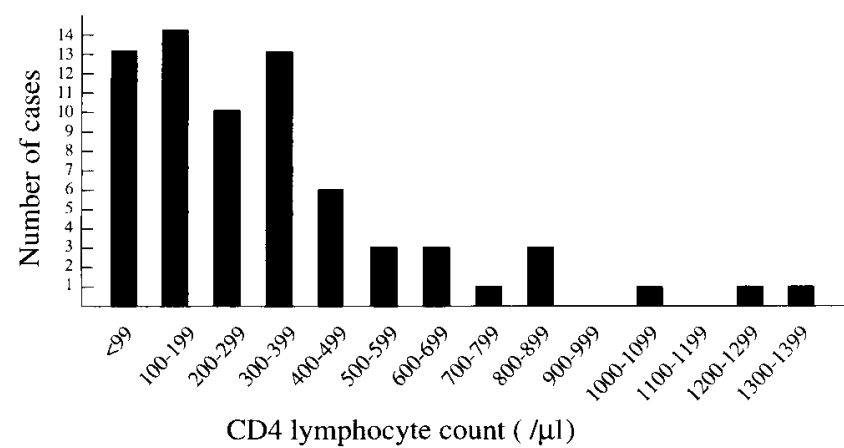

FIGURE 1. The distribution of CD4 lymphocyte counts in the peripheral blood in sixty-nine HIV-1-infected patients with community-acquired pneumonia. noted with respect to the isolated pathogens between HIV1-infected and HIV-uninfected patients, except for M. tuberculosis in two HIV-1-infected patients. Polymicrobial infections were observed in 13 cases of HIV-1-infected patients and one case of HIV-uninfected patients. The mean $( \pm$ SD) of CD4 lymphocyte counts $(/ \mu \mathrm{l})$ at diagnosis by bacterial etiology in HIV-1-infected patients were $260 \pm 212$ in $S$. pneumoniae ( 22 cases), $381 \pm 449$ in $H$. influenzae (9 cases), $405 \pm 291$ in $M$. catarrhalis (8 cases), $127 \pm 127$ in $S$. aureus ( 4 cases), and $415 \pm 270$ in $K$. pneumoniae ( 3 case), respectively. The mean of CD4 lymphocytes counts/ $\mu$ in HIV-1-infected patients with CAP due to M. tuberculosis (2 cases) was 39.

The $\mathrm{MIC}_{50}$ and the $\mathrm{MIC}_{90}$ of penicillin $\mathrm{G}$ against 19 strains of $S$. pneumoniae were $0.78 \mu \mathrm{g} / \mathrm{ml}$ and $1.56 \mu \mathrm{g} / \mathrm{ml}$, respectively (Table 3$)$. Most $(18 / 19 ; 95 \%)$ of the isolated strains of $S$. pneumoniae, therefore, were resistant to penicillin (15 were PISP and 3 were PRSP). The $\mathrm{MIC}_{50}$ and the $\mathrm{MIC}_{90}$ of ampicillin against $S$. pneumoniae were $0.20 \mu \mathrm{g} / \mathrm{ml}$ and 0.39 $\mu \mathrm{g} / \mathrm{ml}$, respectively. These strains were sensitive to erythromycin. Six of 8 strains of $H$. influenzae were positive for $\beta$-lactamase production. The $\mathrm{MIC}_{90}$ of penicillin-G, ampicillin and sultamicillin against 8 strains of $H$. influenzae were $12.5 \mu \mathrm{g} / \mathrm{ml}, 3.13 \mu \mathrm{g} / \mathrm{ml}$, and $1.56 \mu \mathrm{g} / \mathrm{ml}$, respectively. Most of these penicillin-resistant S. pneumoniae $(17 / 18 ; 94.1 \%)$ and $\beta$-lactamase producing $H$. influenzae $(6 / 6 ; 100 \%)$ were isolated from HIV-1-infected patients. The $\mathrm{MIC}_{90}$ of TMPSMZ against both $S$. pneumoniae and $H$. influenzae was $>$ $100 \mu \mathrm{g} / \mathrm{ml}$. It is obvious that TMP-SMZ can no longer be recommended for treatment of CAP in Uganda.

Among 48 patients with identified pathogens, we could evaluate the clinical effectiveness of antimicrobial therapies primarily consisting of parenteral ampicillin followed by oral amoxicillin for 39 patients with bacterial CAP, because 7 pa- 
TABLE 2

Causative organism of community-acquired pneumonia by HIV-status in 99 hospitalized patients

\begin{tabular}{|c|c|c|c|}
\hline Causative organism & $\begin{array}{l}\text { HIV-1 infected } \\
(\mathrm{n}=74) \\
\mathrm{n}(\%)\end{array}$ & $\begin{array}{l}\text { HIV-uninfected } \\
(\mathrm{n}=25) \\
\mathrm{n}(\%)\end{array}$ & $\begin{array}{c}\text { Total } \\
(\mathrm{n}=99) \\
\mathrm{n}(\%)\end{array}$ \\
\hline Streptococcus pneumoniae & $23(31.1)$ & $2(8.0)$ & $25(25.3)$ \\
\hline Haemophilus influenzae & $9(12.2)$ & $1(4.0)$ & $10(10.1)$ \\
\hline Moraxella catarrhalis & $8(10.8)$ & $0(0)$ & $8(8.0)$ \\
\hline Staphylococcus aureus & $4(5.4)$ & $1(4.0)$ & $5(5.0)$ \\
\hline Klebsiella pneumoniae & $3(4.1)$ & $2(8.0)$ & $5(5.0)$ \\
\hline Haemophilus parainfluenzae & $2(2.7)$ & $1(4.0)$ & $3(3.0)$ \\
\hline Mycobacterium tuberculosis & $2(2.7)$ & $0(0)$ & $2(2.0)$ \\
\hline Haemophilus haemolyticus & $1(1.4)$ & $1(4.0)$ & $2(2.0)$ \\
\hline Escherichia coli & $1(1.4)$ & $0(0)$ & $1(1.0)$ \\
\hline Enterobacter cloacae & $1(1.4)$ & $0(0)$ & $1(1.0)$ \\
\hline Strenotrophomonas maltophilia & $1(1.4)$ & $0(0)$ & $1(1.0)$ \\
\hline Unknown & $33(44.6)$ & $18(72.0)$ & $51(51.5)$ \\
\hline Total & $88(118.9)^{*}$ & $26(104.0) \dagger$ & $114(115.2)$ \\
\hline
\end{tabular}

* Percent total $=118.9 \%$ because 13 patients satisfied diagnostic criteria for two or more pathogens.

$\dagger$ Percent total $=104.0 \%$ because one patient satisfied diagnostic criteria for two pathogens.

tients withdrew from the study before evaluation and two patients with CAP due to $M$. tuberculosis were excluded from evaluation. No significant difference in the percentage of good clinical response between HIV-1-infected and HIV-uninfected patients was observed among these 39 patients (Table 4). An etiologic pathogen in one HIV-uninfected patient with poor clinical response was $K$. pneumoniae. Among 6 HIV-1-infected patients with poor clinical response, etiologic pathogens were $S$. pneumoniae in 3 cases, $K$. pneumoniae in 1 case, $H$. influenzae + M. catarrhalis in 1 case and Enterobacter cloacae in 1 case. The percentage of good clinical response in HIV-1-infected patients by etiologic agent were $85 \%(17 / 20)$ in $S$. pneumoniae and $88 \%(7 / 8)$ in $H$. influenzae, and $88 \%(7 / 8)$ in $M$. catarrhalis. One of these enrolled patients with CD4 lymphocyte counts of $2 / \mu l$ died of pneumonia due to a mixed infection of Haemophilus haemolyticus and M. tuberculosis on the 8th day after enrollment. No adverse effects of the antimicrobial agents used in this study were observed.
DISCUSSION

In this study we demonstrated a high rate of HIV-1 infection (75\%) among hospitalized adult patients with CAP. This rate was three- to four-fold higher than the recently reported HIV1 seroprevalence in people attending the AIDS Information Centre or women attending antenatal clinics in Kampala. ${ }^{22,23} \mathrm{~A}$ high HIV seroprevalence among patients with acute respiratory illness was already reported in Burundi (54\%) and Tanzania $(74 \%)$. These data indicate a high HIV seroprevalence rate among the general population of the other countries in Central and East Africa. ${ }^{4,5}$ The CD4 lymphocyte counts in approximately three-fourths of the HIV-infected patients in this study were almost equally distributed less than $400 / \mu 1$, whereas they were clustered in the group with CD4 less than $100 / \mu 1$ in a previous study of US patients. ${ }^{6}$ HIV-infected persons in subSaharan Africa may, therefore, be at risk for CAP even in the early stage of HIV infection. The present clinical and labora-

TABLE 3

Antimicrobial susceptibility of Streptococcus pneumoniae and Haemophilus influenzae as causative pathogens of community-acquired pneumonia

\begin{tabular}{|c|c|c|c|c|}
\hline \multirow{2}{*}{$\begin{array}{c}\text { Organism } \\
\text { (no. of strains) }\end{array}$} & \multirow[b]{2}{*}{ Antimicrobial agent } & \multicolumn{3}{|c|}{$\operatorname{MIC}(\mu \mathrm{g} / \mathrm{ml})$} \\
\hline & & Range & $\mathrm{MIC}_{50}$ & $\mathrm{MIC}_{90}$ \\
\hline \multirow[t]{10}{*}{ S. pneumoniae (19) } & penicillin-G & $0.05-1.56$ & 0.78 & 1.56 \\
\hline & ampicillin & $0.05-0.78$ & 0.20 & 0.39 \\
\hline & sultamicillin & $0.1-1.56$ & 0.39 & 0.78 \\
\hline & cefuroxime & $0.1-1.56$ & 0.78 & 1.56 \\
\hline & cefmenoxime & $0.025-25$ & 0.10 & 1.56 \\
\hline & erythromycin & $0.025-6.25$ & 0.05 & 0.20 \\
\hline & minocycline & $0.05-25$ & 0.78 & 6.25 \\
\hline & gentamicin & $3.25-50$ & 12.5 & 25 \\
\hline & ofloxacin & $0.78-6.25$ & 1.56 & 3.13 \\
\hline & co-trimoxazole & $12.5->100$ & $>100$ & $>100$ \\
\hline \multirow[t]{10}{*}{ H. influenzae (8) } & penicillin-G & $0.78-12.5$ & 3.13 & 12.5 \\
\hline & ampicillin & $0.2-3.13$ & 1.56 & 3.13 \\
\hline & sultamicillin & $0.39-1.56$ & 0.78 & 1.56 \\
\hline & cefuroxime & $0.39-1.56$ & 0.78 & 1.56 \\
\hline & cefmenoxime & $0.006-0.39$ & 0.025 & 0.39 \\
\hline & erythromycin & $1.56-6.25$ & 3.13 & 6.25 \\
\hline & minocycline & $0.39-3.13$ & 1.56 & 3.13 \\
\hline & gentamicin & $1.56-3.13$ & 1.56 & 3.13 \\
\hline & ofloxacin & $0.025-0.1$ & 0.025 & 0.1 \\
\hline & co-trimoxazole & $>100$ & $>100$ & $>100$ \\
\hline
\end{tabular}

MIC $=$ minimum inhibitory concentration. 
TABLE 4

Effectiveness of parenteral ampicillin therapy followed by oral amoxicillin for 39 patients with community-acquired bacterial pneumonia by HIV-status

\begin{tabular}{lccr}
\hline HIV-status & $\begin{array}{c}\text { HIV-1-infected } \\
(\mathrm{n}=32)\end{array}$ & $\begin{array}{c}\text { HIV-uninfected } \\
(\mathrm{n}=7)\end{array}$ & $\begin{array}{c}\text { Total } \\
(\mathrm{n}=39)\end{array}$ \\
\hline Clinical response & $\mathrm{n}(\%)$ & & \\
Good & $26(81.2)$ & $6(85.7)$ & $32(82.1)$ \\
Poor & $6(18.8)$ & $1(14.3)$ & $7(17.9)$ \\
\hline
\end{tabular}

tory data revealed no differences in the severity of CAP based on HIV-status as previously reported..$^{12,13}$

Among bacterial pathogens identified in HIV-1-infected patients, we found not only $S$. pneumoniae (31\%), but also $H$. influenzae $(12 \%)$ and $M$. catarrhalis $(11 \%)$, although only a few of these strains had been identified as pathogens in previous studies in Africa. ${ }^{12,13}$ In our present study, a high isolation rate of $H$. influenzae could be explained by the quantitative culture method using rabbit blood agar, which is highly sensitive for this microorganism. ${ }^{16}$ Distribution of bacterial etiology for CAP among HIV-1-infected persons were similar to those in the US. ${ }^{14}$ The mean CD4 counts among HIV-1-infected patients with CAP due to $S$. aureus or M. tuberculosis were much lower than those due to major bacterial pathogens such as $S$. pneumoniae, $H$. influenzae or $M$. catarrhalis. These data support the view that $S$. aureus is a causative pathogen of pneumonia in HIV-infected persons with an advanced stage of immunosuppression. ${ }^{24}$ We have similarly documented that the CD4 peripheral-blood lymphocyte counts of the majority of patients with pulmonary tuberculosis and HIV-1 infection in Uganda were less than 200/ $\mu 1 .{ }^{24}$ A few cases of CAP due to $M$. pneumoniae or $C$. pneumoniae were reported in a study in Cameroon. ${ }^{13}$ We, however, did not find a four-fold rise of antibody titer for these pathogens in the present study. Previous studies have reported Pneumocystis carinii ( $P$. carinii) pneumonia is uncommon in HIV-infected individuals in sub-Saharan Africa, ${ }^{12,13,25}$ although $P$. carinii is a commonly identified etiologic agent of AIDS-associated CAP in the US. ${ }^{14}$ We also did not encounter cases suspected to be due to $P$. carinii by clinical and radiological manifestations such as tachypnea and reticulonodular shadows during the short period of follow-up in this study. ${ }^{26}$ Recent studies, however, have reported a relatively high frequency of $P$. carinii pneumonia in African patients with AIDS. ${ }^{26,27}$ The diagnostic procedures employing induced sputum or bronchoalveolar lavage with special staining performed on the specimens and longer follow-up for CAP patients with low CD4 lymphocyte counts are also necessary to exclude $P$. carinii pneumonia in sub-Saharan Africa. ${ }^{28}$

Recent studies indicated the successful treatment by shortterm parenteral $\beta$-lactam antibiotics prior to an oral switch for hospitalized patient with uncomplicated CAP. ${ }^{10,11}$ In India, investigators reported that all patients with CAP responded to one week of parenteral penicillin followed by oral antibiotics, with a total therapy duration of 10 days. ${ }^{10}$ No study, however, has evaluated the usefulness of short-term parenteral antibiotic therapy for CAP in HIV-infected individuals, especially in developing countries. In this study, more than $80 \%$ of the patients had good clinical response by short-term parenteral ampicillin followed by oral amoxicillin in both HIV-1-infected and HIVuninfected patients with bacterial CAP. No difference in the percentage of good clinical response between HIV-1-infected and HIV-uninfected patients was observed, although the number of HIV-uninfected patients was small. The low dose of ampicillin, however, may be insufficient to eradicate pathogens in HIV-infected patients with low CD4 lymphocyte counts. We are now developing a study to determine whether higher doses of parenteral ampicillin are more effective.

In this study, we documented a high frequency (95\%) of penicillin resistance in $S$. pneumoniae. Penicillin resistance in $S$. pneumoniae isolated from HIV-infected patients with pneumonia has been reported in Kenya and France, ${ }^{29,30}$ although the frequency of penicillin resistance was still low (17-31\%) in these areas. However, a few cases of clinically observed treatment failure by $\beta$-lactam antibiotics in pneumonia due to PRSP have been reported despite an epidemic of PRSP. ${ }^{31,32}$ We found only three cases of treatment failure for CAP due to PISP (two cases) and PRSP (one case) by short-term parenteral ampicillin therapy despite a very high frequency of penicillin-resistance in isolated $S$. pneumoniae strains. In addition, the rate of $\beta$ lactamase production in $H$. influenzae $(75 \%)$ in our study was also higher than that in other parts of the world. ${ }^{33,34}$ Subsequently, only one case of treatment failure in CAP due to $\beta$ lactamase producing $H$. influenzae was noted. The tissue levels of ampicillin appeared to be higher than the MIC levels of ampicillin against these organisms in most CAP cases. ${ }^{35}$ To our knowledge, this study is the first report of a short-term parenteral antibiotic therapy for CAP in developing countries where PRSP and $\beta$-lactamase producing $H$. influenzae are prevalent.

The present data support the usefulness of short-term parenteral ampicillin therapy followed by oral amoxicillin for patients with bacterial CAP both in HIV-1-infected and HIV-uninfected patients. Treatment failures in cases of CAP due to penicillin-resistant bacterial pathogens and due to unknown etiology, especially in HIV-infected patients, indicate that careful etiologic diagnosis and targeted antimicrobial treatment is important. Further investigation of diagnostic etiologies and clinical effectiveness of short-term parenteral ampicillin therapy prior to an oral switch is required in order to provide proper guidelines for treatment of CAP in developing countries where HIV infection is common.

Acknowledgments: The authors thank Ococi-Jungala and W. Muzawalu for their technical support and S. Ndagire, S. Nansikombi, A. Margret, and I. Serwanga for their patient management. We are grateful to K. Matsumoto and B. W. Nielsen for their critical comments on this study.

Financial support: This work was supported, in part, by a grant from the Ministry of Education, Science and Culture, and from the JapanUS Cooperative Medical Sciences Program on Acute Respiratory Infections and International Cooperation Grant from the Ministry of Health and Welfare, Japan.

Authors' addresses: Hiroyuki Yoshimine, Kazunori Oishi, Hidehiko Takahashi, Hideaki Amano, Kiwao Watanabe, Kamruddin Ahmed, Masaaki Shimada, and Tsuyoshi Nagatake, Department of Internal Medicine and Information and Reference Center, Institute of Tropical Medicine, Nagasaki University, Nagasaki 852-8523, Japan. Francis Mubiru, Hawa Nalwoga, Philip Ombasi, Moses Joloba, Thomas Aisu, and Roy Mugerwa, Department of Medicine and Microbiology, Makerere University, Kampala, Uganda.

Reprint requests: Hiroyuki Yoshimine, Department of Internal Medicine, Institute of Tropical Medicine, Nagasaki University, 1-12-4 Sakamoto, Nagasaki 852-8523, Japan. 


\section{REFERENCES}

1. Leowski J, 1986. Mortality from acute respiratory infections in children under 5 years of age: global estimates. World Health Stat $Q$ 39: 138-144.

2. Kaplan JE, Hu DJ, Holmes KK, Jaffe HW, Masur H, de Cock KM, 1996. Preventing opportunistic infections in human immunodeficiency virus-infected persons: implications for the developing world. Am J Trop Med Hyg 55: 1-11.

3. Jones JL, Hanson DL, Dworkin MS, Kaplan JE, Ward JW, 1998. Trends in AIDS-related opportunistic infections among men who have sex with men and among injecting drug users, 1991-1996. Clin Infect Dis 178: 114-120.

4. Daley CL, Mugusi F, Chen LL, Schmidt DM, Small PM, Bearer E, Aris E, Mtoni IM, Cegielski JP, Lallinger G, Mbaga I, Murray JF, 1996. Pulmonary complication of HIV infection in Dar es Salaam, Tanzania. Role of bronchoscopy and bronchoalveolar lavage. Am J Respir Crit Care Med 154: 105110.

5. Kamanfu G, Mlika-Cabanne NM, Girard PM, Nimubona S, Mpfizu B, Cishako A, Roux P, Coulaud JP, Larouze B, Aubry P, Murray JF, 1993. Pulmonary complications of human immunodeficiency virus infection in Bujumbura, Burundi. Am Rev Respir Dis 147: 658-663.

6. Hirschtick RE, Glassroth J, Jordan MC, Wilcosky TC, Wallace JM, Kvale PA, Markowitz N, Rosen MJ, Mangura BT, Hopewell PC, 1995. Bacterial pneumonia in persons infected with the human immunodeficiency virus. Pulmonary Complications of HIV Infection Study Group. N Engl J Med 333: 845851.

7. Moja PH, Jalil A, Quesnel A, Perol M, Cotte L, Livrozet JM, Boibieux A, Chamson A, Vergnon JM, Lucht F, Tran R, Pozzetto B, Genin C, 1997. Humoral immune response within the lung in HIV-1 infection. Clin Exp Immunol 110: 341-348.

8. Sibellas M, 1966. Treatment of lobar pneumonia in out-patients. J Trop Med Hyg 69: 94-96.

9. Sutton DR, Wicks AC, Davidson L, 1970. One-day treatment for lobar pneumonia. Thorax 25: 241-244.

10. Prabhudesai PP, Kuruvilla T, Tadvi S, 1997. Community-acquired pneumonia: need for a cost-effective approach to treatment. Chest 112: 861-862.

11. Siegel RE, Halpern NA, Almenoff PL, Lee A, Cashin R, Greene JG, 1996. A prospective randomized study of inpatient iv. antibiotics for community-acquired pneumonia. The optimal duration of therapy. Chest 110: 965-971.

12. Aderaye G, 1994. Community-acquired pneumonia in adults in Addis Ababa: etiologic agents and the impact of HIV infection. Tuber Lung Dis 75: 308-312.

13. Koulla-Shiro S, Kuaban C, Belec L, 1996. Acute communityacquired bacterial pneumonia in human immunodeficiency virus (HIV) infected and non-HIV infected adult patients in Cameroon: aetiology and outcome. Tuber Lung Dis 77: 4751.

14. Mundy LM, Auwaerter PG, Oldach D, Warner ML, Burton A, Vance E, Gaydos CA, Joseph JM, Gopalan R, Moore RD, Quinn TC, Charache P, and Bartlett JG, 1995. Communityacquired pneumonia: impact of immune status. Am J Respir Crit Care Med 152: 1309-1315.

15. Saito A, Miki F, Oizumi K, Rikitomi N, Watanabe A, Koga H, Niki Y, Kusano N, 1999. Clinical evaluation methods for new antimicrobial agents to treat respiratory infections: Report of the committee for the respiratory system, Japan Society of Chemotherapy. J Infect Chemother 5: 110-123.

16. Crawford JJ, Barden L, Kirkman, JB, 1969. Selective culture media to survey the incidence of Haemophilus species. Appl Microbiol 18: 646-649.

17. Kishimoto T, Kubota Y, Matsudhima T, Izutsu H, Matsumoto A Morikawa T, Soejima R, Morikawa T, Kawagoe K, 1996. Assay of specific anti-Chlamydia pneumoniae antibodies by ELISA method. 1. Evaluation of ELISA kit using outer membrane complex. Jap J Infect Dis 70: 821-829.

18. Tateda K, Murakami H, Ishii Y, Furuya N, Matsumoto T, Ya- maguchi K, 1998. Evaluation of clinical usefulness of the microplate agglutination test for serological diagnosis of legionella pneumonia. J Med Microbiol 47: 325-328.

19. Onyango FE, Steinhoff MC, Wafula EM, Wariua S, Musia J, Kitonyi J, 1993. Hypoxaemia in young Kenyan children with acute lower respiratory infection. BMJ 306: 612-615.

20. A report from the committee for the susceptibility of antimicrobial agents, 1992. Tokyo: Japanese Society of Chemotherapy.

21. National Committee for Clinical Laboratory Standards, 1993 Methods for Dilution Antimicrobial Susceptibility Test for Bacteria That Grow Aerobically, Vol 13. Third edition. Approved standard M7-A3. Villanova, PA: National Committee for Clinical Laboratory Standards.

22. Muller O, Barugahare L, Schwartlander B, Byaruhanga E, Kataaha P, Kyeyune D, Heckmann W, Ankrah M, 1992. HIV prevalence, attitudes and behavior in clients of a confidential HIV testing and counseling centre in Uganda. AIDS 6: 869874.

23. Kilian AHD, Gregson S, Ndyanabangi B, Walusaga K, Kipp W, Sahlmuller G, Garnett GP, Asiimwe-Okiror G, Kabagambe G, Weis P, von Sonnenburg F, 1999. Reductions in risk behavior provide the most consistent explanation for declining HIV-1 prevalence in Uganda. AIDS 13: 391-398.

24. Boschini A, Smacchia C, Di Fine M, Schiesari A, Ballarini P, Arlotti M, Gabrielli C, Catellani G, Genova M, Pantani P, Lepri AC, Rezza G, 1996. Community-acquired pneumonia in a cohort of former injection drug users with and without human immunodeficiency virus infection: incidence, etiologies, and clinical aspects. Clin Infect Dis 23: 107-113.

25. Lucas SB, Odida M, Wabinga H, 1991. The pathology of severe morbidity and mortality caused by HIV infection in Africa. AIDS 5 (supp 1): S143-S148.

26. Malin AS, Gwanzura LK, Klein S, Robertson VJ, Musvarire P, Mason PR, 1995. Pneumocystis carinii pneumonia in Zimbabwe. Lancet 346: 1258-1261.

27. Mahomed AG, Murray J, Klempman S, Richards G, Feldman C, Levy NT, Smith C, Kallenbach J, 1999. Pneumocystis car inii pneumonia in HIV infected patients from South Africa. East Afr Med J 76: 80-84.

28. Cameron RB, Watt JC, Kasten B, 1979. Pneumocystis carini pneumonia: an approach to rapid laboratory diagnosis. Am J Clin Pathol 72: 90-93.

29. Paul J, Kimari J, Gilks CF, 1995. Streptococcus pneumoniae resistant to penicillin and tetracycline associated with HIV seropositivity. Lancet 346: 1034-1035.

30. Meynard JL, Barbut F, Blum L, Guiguet M, Chouaid C, Meyohas MC, Picard O, Petit JC, Frottier J, 1996. Risk factors for isolation of Streptococcus pneumoniae with decreased susceptibility to penicillin $\mathrm{G}$ from patients infected with human immunodeficiency virus. Clin Infect Dis 22: 437-440.

31. Watanabe H, Sato S, Kawakami K, Watanabe K, Oishi K, Rikitomi N, Ii T, Ikeda H, Sato A, Nagatake T, 2000. A comparative clinical study of pneumonia by penicillin-resistant and sensitive Streptococcus pneumoniae in a community hospital. Respirology 5: 59-64.

32. Dowell SF, Smith T, Leversedge K, Snitzer J, 1999. Failure of treatment of pneumonia associated with highly resistant pneumococci in a child. Clin Infect Dis 29: 462-463.

33. Felmingham D, Robbins MJ, Tesfaslasie Y, Harding I, Shrimpton S, Gruenerg RN, 1998. Antimicrobial susceptibility of community-acquired lower respiratory tract bacterial pathogens isolated in the UK during the 1995-1996 cold season. $J$ Antimicrob Chemother 41: 411-415.

34. Blondeau JM, Suter M, Borsos S, 1999. Determination of the antimicrobial susceptibilities of Canadian isolates of Haemophilus influenzae, Streptococcus pneumoniae and Moraxella catarrhalis. Canadian Antimicrobial Study Group. J Antimicrob Chemother 43 (Suppl. A): 25-30.

35. Siegel RE, 1999. The significance of serum vs. tissue levels of antibiotics in the treatment of penicillin-resistant Streptococcus pneumoniae and community-acquired pneumonia. Are we looking in the wrong place? Chest 116: 535-538. 